\title{
Más allá del comparatismo. Palabra e imagen en el Siglo de Oro: conexiones y límites
}

\author{
Natalia FERnÁNDEZ RodRÍGUEZ \\ Universität Bern
}

\begin{abstract}
El vínculo texto-imagen no es únicamente una cuestión de comparatismo, ni se puede limitar al eco del ut pictura poesis horaciano. Las relaciones intermediales, ampliamente entendidas, son portavoces de estructuras culturales profundas que nos hablan de los modos de ver de toda una época. En concreto, durante el Siglo de Oro, la conexión entre la imagen y la palabra se aprovechó en contextos diversos y con intenciones distintas. $Y$ es precisamente esta versatilidad la que se trata de mostrar en la colección de estudios que conforman este volumen monográfico.
\end{abstract}

Keywords: ut pictura poesis, intermedialidad, Siglo de Oro, imagen, poder.

Something like the Renaissance notion of ut pictura poesis and the sisterhood of the arts is always with us. The dialectic of Word and Image seems to be a constant in the fabric of signs that a culture weaves around itself.

W.J.T. Mitchell, 1986

Es inevitable. Cuando nos internamos en esos pasadizos, intrincados a veces, en los que convergen de alguna manera lo legible y lo visible, siempre aparece Horacio con aquella máxima ya casi atemporal del ut pictura poesis ${ }^{\text {. }}$ Aparece Horacio y, junto a él, Simónides de Ceos, el primero en formular la conexión esencial entre poesía y pintura con un quiasmo llamado a convertirse en uno de los loci más repetidos a partir del Renacimiento: la poesía es una pintura elocuente y la pintura es una poesía muda. Son los dos pilares clásicos que sustentan el comparatismo interartístico en sus dos sentidos fundamentales: mimético y pragmático. Con su propuesta de interconexión entre las artes, Simónides estaba intuyendo nada menos que la doctrina de la imitación que, más tarde, Platón y, de forma decisiva, Aristóteles situarían en la base de la teoría artístico-literaria occidental. Horacio, por su parte, no pretendía comparar poesía y pintura de forma absoluta, sino únicamente equiparar la reacción de los receptores ante obras de distinta naturaleza, literaria o visual:

I Tomo el término pasadizo del título del ensayo de Vicente Luis Mora (2008) sobre los espacios simbólicos entre el arte y la literatura. 
Pintura y poesía se parecen, pues en ambas se ofrecen obras que gustan más vistas de lejos; y otras, no estando cerca, desmerecen. Cuál debe colocarse en parte obscura, cuál de la luz no tema los reflejos ni del perito la sutil censura por la primera vez agrada aquella esta, diez veces vista, aún es más bella².

Un guiño temprano a la estética de la recepción que terminaría diluyéndose en una fusión casi total de las artes cuando el sintagma se desgajó de su contexto originario para convertirse en un fecundo -y, en algunos momentos, controvertido- topos teórico. Hacía falta que se diera un entramado de circunstancias culturales, en sentido amplio, para que el hermanamiento artístico terminara configurándose como piedra angular de todo un sistema estético ${ }^{3}$. Ese proceso tuvo lugar justamente durante el Renacimiento. Por un lado, el Trecento humanista había recuperado y prestigiado gran parte de la tradición retórica que cimentaba las conexiones poesía-pintura. El propio Petrarca llegó a definir el oficio del poeta en términos cuasi pictóricos, haciendo referencia a los colores empleados para adornar la realidad, la verdad que resplandece bajo la dificultad, el velo que cubre la apariencia de las cosas... y anticipando, con ello, en varios siglos las teorizaciones barrocas del ingenio ${ }^{4}$. Por otro, la primera mitad del Quattrocento vio emerger una teoría pictórica fuertemente apegada a la retórica o, si queremos, una concepción retórica de la pintura. En I435, Leon Battista Alberti empleó términos como historia, invención y composición para explicar el proceso creador del cuadro; un léxico tomado directa y conscientemente de los tratados de retórica. No podía ser de otra manera. El primer teórico de la perspectiva no contaba con un vocabulario específicamente artístico que le permitiera elaborar una teoría independiente. Por eso, la teorización sobre la imagen artística nació unida -inevitablemente unida-a la teorización sobre la palabra. Pero eso no fue todo. La tan reiterada ausencia de las artes plásticas del selecto grupo de las artes liberales explicó que la vinculación de la pintura con la poesía asegurase un prestigio del que, en rigor, carecía:

Los teóricos defendieron siempre la nobleza de este arte [la pintura] y la necesidad de incluirla en el sistema de las artes liberales aludiendo tanto a su

\footnotetext{
2 Es la traducción de Tomás de Iriarte publicada en 1805.

3 Los estudios clásicos, inaugurales, sobre esta consolidación de toda una concepción artística a partir del hermanamiento poesía-pintura son el de Lee (I940) y el de Kristeller (I95I: III-II7).

4 En las Epistolae Seniles, XIII, 2.
} 
utilidad social y religiosa como al importantísimo contenido intelectual que conllevaba. Y no encontraron una fórmula más afortunada para argumentar en favor de estas pretensiones que la famosa ecuación antigua: ut pictura poesis. Asimilando la creación pictórica a una actividad cuya nobleza y liberalidad no admitían dudas, como la poesía, demostraban por comparación la bondad intelectual de la creación artística (Portús, 2000: 178).

Más allá de lo puramente estético, el ut pictura poesis adquirió un valor militante aprovechable -y, de hecho, bien aprovechado- tanto desde la teoría pictórica como desde la poesis misma, donde resonarían vigorosos los ecos de Simónides y Horacio hasta los albores del siglo XVIII. Pero, a pesar, como decíamos, de su valor decisivo para la consolidación de un sistema moderno de las artes, este trasvase del parangón interartístico hacia la recién nacida teoría de la pintura no implicó, ni mucho menos, su desaparición de la teoría literaria. En la España del Siglo de Oro, la reflexión sobre la creación poética, desde Herrera a Gracián, corrió pareja a la afirmación cada vez más intensa de los valores plásticos y artísticos -visuales, en definitiva- de la palabra. Hasta que, en el siglo XviI, con el avance hacia el Barroco y la priorización ubicua de la imagen y su poder emotivo, la mención explícita al comparatismo fue dejando paso a un análisis más profundo de las implicaciones formales y los valores afectivos del sustrato pictórico de la poesis 5 . En I602, Luis Alfonso de Carvallo apeló, de forma más explícita que nadie hasta la fecha, al poder visualmente evocador de la palabra:

Y quando supiere el poeta la cosa que ha de describir, para que salga la descripción perfecta enterarse ha muy bien de lo que ha de describir, y representarlo ha en su fantasía como si con los ojos lo hubiera visto, y luego conforme la figura que dello ha concebido lo que deziendo por las más proprias palabras que hallare, y por los vocablos que mas propriamente lo signifiquen, desmenuçándolo parte por parte por el estylo y orden que mejor lo dé a entender, para que mediante estas cosas el oyente venga a concebir en su imaginativa la figura que en la suya antes estaba, de modo que más le parezca verla que oyrla. En esta descripción imita al pintor el poeta más que en otra cosa (73).

Carvallo se sitúa en los límites del comparatismo al definir ese tipo de descripción tan esencialmente barroca que Hagstrum (I968: xii) -en un ensayo, por cierto, sobre las artes hermanas-, denominaría pictorialista; una écfrasis en su sentido originario.

La comparación interartística, tal como se consolidó en el Renacimiento, no apuntó, por tanto, en una única dirección; ni siquiera si dejamos de lado

5 Sobre el tratamiento de la comparación poesía-pintura en la teoría literaria de la España del Siglo de Oro, de Herrera a Cascales, puede verse Fernández Rodríguez (2016). 
la cuestión del prestigio del artista y nos limitamos a la reflexión estética. El ut pictura poesis -o el ut poesis pictura, si queremos- sirvió para indagar en las problemáticas tradicionales de la obra de arte entendida en su dimensión semiológico-comunicativa: desde la naturaleza del proceso creador, la imitación, la construcción formal o composición, hasta el propósito de la obra y los efectos -emocionales, psicológicos, perceptivos- en el receptor. Bien se profundizase en el sentido de la mimesis como germen de la creación, bien se intentasen mover los afectos del espectador-lector -más le parezca verla que oirla... decía arriba Carvallo-, múltiples frentes de interacción palabra-imagen se mantuvieron activos durante todo el Siglo de Oro emergiendo en textos -y contextos- poliédricos de tal manera que el comparatismo, como tal, terminó trascendiéndose a sí mismo. Mitchell, el autor que citamos al comienzo de estas líneas, alertó en otro lugar hace algunos años:

Comparison itself is not a necessary procedure in the study of image-text relations. The necessary subject matter is, rather, the whole ensemble of relations between media, and relations can be many other things besides similarity, semblance and analogy (Mitchell, 1994: 89).

Cuando nos propusimos dedicar este número monográfico a las relaciones texto-imagen en el Siglo de Oro, partimos del sustrato inevitable del $u t$ pictura poesis para abordarlo en ese sentido amplio que logra arrojar nuevas miradas sobre la construcción cultural y los parámetros estéticos y creativos de toda una época. Los ocho trabajos que se incluyen en este volumen se centran en corpus muy dispares para reflexionar desde perspectivas distintas sobre el modo en que se produce ese ensamblaje intermedial que dice Mitchell. Y ello en un contexto, la España áurea, permeable por definición al aprovechamiento retórico y afectivo de la imagen tanto como a la indagación en el potencial imaginativo de la palabra. Son tres los bloques temáticos en que hemos organizado las contribuciones: imagen, texto y religión; imagen, texto y poder; y poesía y artes figurativas. Cécile Vincent-Cassy y Fernando Baños ilustran, desde enfoques muy distintos, la problemática de la imagen en contextos vinculados a la devoción. Rocío Cárdenas Luna y Pedro Ruíz Pérez, en un artículo conjunto, Antonio Sánchez Jiménez y Jesús Ponce Cárdenas indagan en algunos modos en que la imagen y su descripción pueden relacionarse con los focos de poder. Y Roland Béhar, Adrián J. Sáez y $\mathrm{M}^{\mathrm{a}}$ Cristina Quintero profundizan en las relaciones, temáticas o formales, entre la poesía áurea y otras artes. Ut pictura poesis, por tanto, y algo más; algo más allá del comparatismo que intenta dar cuenta de esas intersecciones múltiples, esos pasadizos laberínticos entre texto e imagen en el Siglo de Oro. 
La importancia del elemento visual en el ámbito religioso -con valor pedagógico, emotivo o devocional- está fuera de toda duda. Más allá de la fuerza escópica inherente a la génesis de la hagiografía o de la evidente intención demostrativa de la dramaturgia sacra medieval, durante el siglo XVI se hace cada vez más explícita la presencia de lo visible en contextos de raigambre piadosa. A una creciente confianza en lo imaginativo epitomizada por la composición viendo el lugar de San Ignacio, se unió la tan citada sesión XXV del Concilio de Trento, con la recomendación netamente contrarreformista de integrar las imágenes en el culto ${ }^{6}$. Ambas explicaron, en parte al menos, una tendencia a la demostración ad oculos que se irradió hacia los entresijos del discurso devocional. Las verdades de la fe, los episodios y figuras sagrados o los integrantes del santoral se configuraron como verdaderos objetos icónico-textuales aprovechables en múltiples contextos: desde la hagiografía impresa, hasta las tablas de la comedia religiosa barroca. Cécile Vincent-Cassy ${ }^{7}$ abre el volumen reflexionando precisamente sobre la relación del mundo católico con la imago a partir del estudio de la imaginería mariana y su presencia en el que considera un subgénero dentro de la comedia barroca: las comedias de imágenes milagrosas. La autora sitúa la cuestión de la iconografía de la Virgen en el centro del asunto capital en la religiosidad barroca en lo que a visualismo se refiere: el juego entre la materialidad y la referencialidad, entre la imagen tangible y el prototipo tan discutido precisamente en Trento. Y sostiene que fue el teatro un medio privilegiado para hacer visible el debate sobre la imagen como retrato, como copia en trampantojo de la Virgen.

Aparte de la revalorización per se de la imagen, el tridentino impulsó un prurito de autenticidad histórica que se filtró hacia la concepción misma de la hagiografía y de todos sus componentes -textuales y visuales-. Es ahí donde se sitúa justamente el artículo de Fernando Baños centrado en la función de la palabra y la imagen en los paratextos -prólogos, colofones, portadas e ilustraciones- de los flores sanctorum castellanos del siglo XVI. El autor sostiene que esos elementos constituyen un instrumento de autoridad en consonancia con la exigencia de verismo. Su análisis, cuyo presupuesto metodológico implica la comparación de los santorales pre y postridentinos, parte del estudio de los proemios - de importancia creciente en la época posterior al Concilio- como argumentarios de la veracidad a partir de varios frentes: el tratamiento y depuración de la materia apócrifa, la selección de fuentes, la confección de un elenco de santos históricos o las dedicatorias

6 Los Ejercicios espirituales de San Ignacio de Loyola aparecieron en Roma en I548, y la sesión XXV del tridentino se celebró en diciembre de 1553.

7 Una primera versión de este trabajo se presentó en el Congreso Internacional Lo que vemos, lo que nos mira. Culturas y prácticas visuales en España y Latinoamérica (siglos XVI-XXI), celebrado en la Universidad de Berna los días 27 y 28 de octubre de 2017. 
a poderosos. Y, en conexión con ellos, las imágenes e ilustraciones se revelan como complemento solidario de los textos en el objetivo primordial de conferir autoridad al volumen mediante divisas, emblemas o retratos de personas o instituciones ilustres. «Palabra e imagen -concluye Baños rescatando el título del monográfico-construyen una autoridad más sólida que nunca». Ut poesis pictura, podríamos decir aquí; como el texto, la imagen viene a convertirse en un testimonio visible de la seriedad que quiso mostrar -y demostrar- la hagiografía postridentina.

El artículo de Baños, que indaga en las virtualidades legitimadoras de la complementariedad texto-imagen, sirve de transición hacia el segundo de los bloques de contenido integrados en el volumen: imagen, texto y poder. La presencia de lo visual en contextos laudatorios -arquitectura efímera, escudos, emblemas o divisas, imágenes simbólicas, retratos- fue una constante durante el Siglo de Oro que pudo muy bien complementarse con la palabra. Rocío Cárdenas Luna y Pedro Ruíz Pérez estudian el doble valor artístico y pragmático- de los retratos incluidos en los seis volúmenes líricos de don Bernardino de Rebolledo, publicados entre i650 y i66o. Por un lado, valoran la presencia de la imagen propia como marca autorial y editorial, y la sitúan en la órbita de todo un género de retrato que resalta la filiación aristocrática del escritor. Por otro, reparan en la excepcionalidad del hecho de que don Bernardino no incluyese únicamente su retrato sino el de los dedicatarios -sobre todo, dedicatarias- de su obra. Los rasgos -indumentaria, gestos, posición- destacados en las imágenes constituyen la proyección visual de las dedicatorias en verso. $\mathrm{Y}$, juntos, textos e imágenes, vienen a cumplir una función laudatoria en consonancia con la actividad diplomática del escritor. Un ejemplo de la coexistencia texto-imagen como expresión de las claves del poder, en concreto de la misión de Felipe IV, es el que estudia Antonio Sánchez Jiménez. Plantea la comparación de una empresa de Lope de Vega, Nondum erumpit, y el soneto de Francisco Gómez de Reguera que lo acompañó en las Empresas de los reyes de Castilla y León, «Mientras que rompe del oscuro velo». Más allá de la importancia de este ejemplo como testimonio de la afición lopesca por la pintura, Sánchez Jiménez se centra en las diferencias temáticas entre empresa y soneto; un desfase que pone de manifiesto el desacuerdo básico entre el Fénix y Gómez de Reguera en su valoración del monarca. Sin alejarnos del contexto de Felipe IV, Jesús Ponce Cárdenas ${ }^{8}$ analiza las relaciones texto-imagen-poder a partir de la Silva topográfica al Buen Retiro, un poema descriptivo de Manhoel de Gallegos, compuesto con una intención laudatoria y legitimadora del palacio real. Ese propósito primario se articula literariamente mediante una intersección

8 Este trabajo se presentó en el Congreso Internacional Lo que vemos, lo que nos mira... mencionado en la nota anterior. 
poesía-pintura operada en varios niveles. La descripción de obras pictóricas -écfrasis en sentido restringido- constituye el grueso del poema y es a partir de ahí como la teoría del arte se logra poner al servicio del encomio y la laudatio. Un ejemplo vívido del ut pictura poesis convertido en gesto político; de la proyección pragmática que podía asumir la conexión interartística.

Y de relaciones interartísticas en su sentido más puramente estético y semiológico tratan los tres artículos restantes. Desde la reflexión sobre las posibilidades y límites de la transposición intermedial hasta las intersecciones temáticas entre las artes plásticas y la poesía, los autores nos permiten acercarnos a los versos áureos desde múltiples, e iluminadoras, perspectivas. Roland Béhar analiza dos sonetos garcilasianos en relación con la mayólica, un arte de la cerámica de prestigio indudable durante el Renacimiento italiano y que el toledano debió conocer -y apreciar- en cierto detalle. Dos poemas de temática mitológica son los elegidos por Béhar para mostrar cómo su sustrato escópico, sustentado de forma explícita desde los verba videndi, puede estudiarse desde una posible influencia de las piezas de mayólica. La importancia del sustrato artístico en la obra quevediana es el objeto de los dos artículos que cierran el volumen. Adrián J. Sáez analiza la conexión poesía-escultura en el «Retrato de Lisi en mármol» teniendo en cuenta las dos versiones del madrigal, una manuscrita, conservada en la Biblioteca Nacional (Mss/3796) y la incluida en El Parnaso Español. Sáez sostiene que los textos de Quevedo establecen una reescritura artística con una composición de Groto, en el sentido de que intensifican, en consonancia con la mirada estética del Barroco, el foco en la teoría artística. El análisis se articula en dos aspectos clave: el modo en que las ideas sobre el arte se trasladan al poema y la pertinencia de estas disquisiciones estéticas en el contexto concreto de la poesía amorosa de raigambre petrarquista, donde la referencia a la dama de mármol constituye un elocuente símil de la proverbial dureza de la dame sans merci. Es un ejemplo ilustrativo del fuerte sustrato artístico del paradigma de la poesía amorosa; una vuelta de tuerca más al ut pictura poesis. Precisamente $\mathrm{M}^{\mathrm{a}}$ Cristina Quintero, en el artículo que cierra el dossier, se fija también en Quevedo, en concreto en tres sonetos, de tono satírico-burlesco, para analizar la representación de la mujer a partir de la confluencia de dos temas: el literario del desengaño y el pictórico del vanitas. La autora sostiene que ambos son proyecciones de la mirada, realizaciones de un modo de ver el mundo desde un prisma que prioriza la conciencia de lo efímero. Y, en los sonetos, el cuerpo femenino se convierte en testimonio visible de esa temporalidad dándole la vuelta al canon estético del paradigma petrarquista y abriendo las puertas a una reflexión sobre los límites de la representación artística.

Ocho artículos, en definitiva, que rastrean múltiples posibilidades de relación palabra-imagen en el Siglo de Oro y que, sobre todo, permiten abor- 
dar temáticas, géneros y textos desde un nuevo punto de vista que abunda en la transdisciplinariedad y pone de relieve la enriquecedora conexión interartística que caracterizó la estética renacentista y barroca.

El volumen se completa con una sección Varia compuesta por dos aportaciones: la transcripción preparada por Esther Inniger de la conversación entre Gustavo Guerrero y Juan Gabriel Vásquez que tuvo lugar en la Universidad de Berna el 4 de mayo de 20I7. Y un trabajo de Mieke Bal cuya primera versión se presentó en el Congreso Internacional Lo que vemos, lo que nos mira. Culturas y prácticas visuales en España y Latinoamérica (siglos XVI-XXI), celebrado en la Universidad de Berna durante los días 27 y 28 de octubre de 2017. En la Conversación, Gustavo Guerrero, catedrático de Literatura y Cultura Hispanoamericana en la Univerisdad Cergy-Pontoise, empleó diversas citas de Vásquez para recorrer toda la obra novelesca del escritor colombiano, invitado en Berna en el marco de la «Friedrich Dürrenmatt Gastprofessur». El artículo de Mieke Bal es una reflexión sobre la relevancia política del arte a partir de diversas obras del siglo XxI, en especial de la artista colombiana Doris Salcedo. Bal postula un arte no tanto activista como activador; un arte que mueva los afectos del público haciéndole tomar conciencia de las grandes tragedias del presente.

Deseo expresar mi agradecimiento a Bénédicte Vauthier, Esther Inniger y Melanie Würth por su lectura atenta de los trabajos aquí incluidos y su labor editorial.

\section{Bibliografía}

Carvallo, Luis Alfonso de, Cisne de Apolo, eds. Alberto Porqueras Mayo \& Joaquín de Entrambasaguas, Madrid, Aldus, 1958.

Fernández Rodríguez, Natalia, «El sentido de la comparación poesía-pintura en la teoría literaria de la España áurea», Versants, 63.3, 2016, pp. 59-77. Hagstrum, Jean H., The Sister Arts: The Tradition of Literary Pictorialism and English Poetry from Dryden to Gray, Chicago, University of Chicago Press, I968.

Horacio, Arte Poética de Horacio o Epístola a los Pisones traducida en verso castellano, en Colección de Obras en verso y prosa de D. Tomás de Yriarte, IV, Madrid, Imprenta Real, I805, pp. I-I24.

Kristeller, Paul Oscar, «The Modern System of the Arts: A Study in the History of Aesthetics. Part I», Journal of the History of Ideas, I2.4, I95I, pp. 496527 . 
Lee, Rensselaer W., «Ut pictura poesis : the humanistic theory of painting», The Art Bulletin, 22.4, 1940, pp. 197-269.

Mitchell, W.J.T., Iconology, Image, Text, Ideology, Chicago-Londres, The University of Chicago Press, 1986.

- Picture Theory, Londres, The University of Chicago Press, 1994.

Mora, Vicente Luis, Pasadizos. Espacios simbólicos entre arte y literatura, Madrid, Páginas de Espuma, 2008.

Portús Pérez, Javier, «Ut pictura poesis en la España del Barroco: una aproximación desde su iconografía», en Calderón de la Barca y la España del Barroco, coord. José Mํㅡㄹ Díz Borque, Madrid, Sociedad Estatal España Nuevo Milenio, 2000, pp. I77-I94. 